\title{
Ovarian cancer in younger vs older women: a population-based analysis
}

\author{
JK Chan ${ }^{*, 1,3}$, R Urban ${ }^{1,3}$, MK Cheung ${ }^{1,3}$, K Osann ${ }^{4}$, A Husain ${ }^{1,3}$, NN Teng ${ }^{1,3}$, DS Kapp ${ }^{2,3}$, JS Berek ${ }^{1,3}$ and \\ GS Leiserowitz ${ }^{5}$
}

'Division of Gynecologic Oncology, 875 Blake Wilbur Drive, Stanford, CA 94305, USA; ²Division of Radiation Oncology, 875 Blake Wilbur Drive, Stanford, CA 94305, USA; ${ }^{3}$ Stanford Cancer Center, 875 Blake Wilbur Drive, Stanford, CA 94305, USA; ${ }^{4}$ Division of Hematology/Oncology, Chao Family Comprehensive Cancer Center, University of California, Irvine - Medical Center, 101 The City Drive, Orange, CA 92868, USA; ${ }^{5}$ Division of Gynecology

Oncology, University of California, Davis Cancer Center, 4501 X Street, Sacramento, CA, 95817, USA

To compare the clinico-pathologic prognostic factors and survival of younger vs older women diagnosed with epithelial ovarian cancer. Demographic, clinico-pathologic, treatment, and surgery information were obtained from patients with ovarian cancer from the Surveillance, Epidemiology, and End Results Program from 1988 to $200 \mathrm{I}$ and analysed using Kaplan-Meier estimates. Of 28 I 65 patients, 400 were $<30$ years (very young), I I 60I were 30-60 (young), and I6 I 64 were > 60 (older) years of age. Of the very young, young, and older patients, 26 I (65.3\%), 4664 (40.2\%), and 3643 (22.5\%) had stage I-II disease, respectively (P<0.00I). Across all stages, very young women had a significant survival advantage over the young and older groups with 5-year disease-specific survival estimates at $78.8 \%$ vs 58.8 and $35.3 \%$, respectively $(P<0.001)$. This survival difference between the age groups persists even after adjusting for race, stage, grade, and surgical treatment. Reproductive age ( $16-40$ years) women with stage I-|| epithelial ovarian cancer who received uterine-sparing procedures had similar survivals compared to those who underwent standard surgery (93.3\% vs $91.5 \%, P=0.26)$. Younger women with epithelial ovarian cancer have a survival advantage compared to older patients.

British Journal of Cancer (2006) 95, I3|4-1320. doi: I0.1038/sj.bjc.6603457 www.bjcancer.com

Published online 31 October 2006

(c) 2006 Cancer Research UK

Keywords: ovarian cancer; young; uterine-sparing; survival

As the most lethal of the gynaecologic malignancies, ovarian cancer remains the fifth most common cause of cancer-related death for women in the United States. An estimated 25580 new cases of ovarian cancer were diagnosed in the United States in the year 2004, with 16090 deaths associated with this disease (Jemal et al, 2004). Despite advances in surgical and systemic treatment, the 5-year survival of advanced stage patients with ovarian cancer remains below 30\% (Nguyen et al, 1993; Parker et al, 1996; Jemal et al, 2004; Ries et al, 2004). However, invasive epithelial ovarian cancer is largely a disease of postmenopausal women with reproductive-age women comprising only $20 \%$ of all patients (Smedley and Sikora, 1985; Swenerton et al, 1985; Plaxe et al, 1993; Rodriguez et al, 1994). Previous studies on young patients with ovarian cancer have reported survival rates as high as $75 \%$ across all stages compared to $40 \%$ in the overall population.

Some reports have indicated that younger age is not an independent prognostic factor for improved survival, suggesting that the survival advantage of the younger patients may be attributed to the increased frequency of early-stage, lower grade

*Correspondence: Dr JK Chan, Division of Gynecologic Oncology, Department of Obstetrics and Gynecology, Stanford University School of Medicine, Stanford Cancer Center, 875 Blake Wilbur Drive, MC 5827, Stanford, CA 94305, USA; E-mail: johnchan@stanford.edu

Received 25 July 2006; revised 27 September 2006; accepted 30 September 2006; published online 31 October 2006 disease, and tumours of low malignant potential (Massi et al, 1996; Duska et al, 1999). Nonetheless, several other published studies have specified age as a significant prognostic factor, with older patients faring less well than younger women (Smedley and Sikora, 1985; Swenerton et al, 1985; Yancik et al, 1986; Omura et al, 1991; Gloecker-Ries, 1993; Ries, 1993; Thigpen et al, 1993; Kosary, 1994; Rodriguez et al, 1994; Lee et al, 1999; Brun et al, 2000; Schildkraut et al, 2000; Barnholtz-Sloan et al, 2003; Chan et al, 2003; O'Malley et al, 2003).

Many of these studies are institutional-based analyses comprising a small number of patients. Furthermore, most reports originated from academic institutions and clinical trials data with associated biases and outcomes that may not reflect the general population (Averette et al, 1995; Barnholtz-Sloan et al, 2003; Chan et al, 2003). Prior studies that have used data from national registries included information collected from 1973 to 1997 (Yancik et al, 1986; Ries, 1993; Kosary, 1994; Barnholtz-Sloan et al, 2003). Since that time, there have been important changes that have affected the care of ovarian cancer patients. In addition, many studies have not thoroughly evaluated important clinicopathologic prognostic factors. Consequently, there are limited population-based studies with detailed surgical staging and pathology data that have evaluated the demographics, clinicopathologic, and survival outcomes of younger women diagnosed with epithelial ovarian cancer.

In this study of over 28000 epithelial ovarian cancer patients, we propose to determine if young age is an independent factor 
associated with improved survival and identify the clinicopathologic prognostic factors associated with the survival of younger patients.

\section{MATERIALS AND METHODS}

Demographic, clinico-pathological, treatment, and survival information on 28165 women diagnosed with primary epithelial ovarian cancer during the period from 1988 to 2001 were extracted from the Surveillance, Epidemiology and End Results (SEER) database of the United States National Cancer Institute. All patients with low malignant potential tumours of the ovary were excluded from our analysis. Patients diagnosed with germ cell, sarcomas, and sex cord stromal histologic cell types were excluded. Data are reported from 12 population-based registries that represent approximately $14 \%$ of the US population including San Francisco-Oakland, Connecticut, metropolitan Detroit, Hawaii, Iowa, New Mexico, Seattle (Puget Sound), Utah, metropolitan Atlanta, Alaska, San Jose-Monterey, and Los Angeles (Hankey et al, 1999).

To further define the young patients with epithelial ovarian cancer, we divided our young patient population into two subgroups, $<30$ and $30-60$, which we arbitrarily called the very young and young groups $v s$ the older group $>60$ years. The race classifications of the SEER program were categorised into four groups: White, Black, Asian, and Others. Asians were defined as Chinese, Japanese, Korean, Vietnamese, and Filipina. All other race and ethnicity classifications were defined as Others. Surgical treatment was classified as either absent, uterine-sparing, or standard. Uterine-sparing surgeries were defined as surgeries that did not include a hysterectomy whereas standard surgeries included those reported to have had a hysterectomy and/or radical debulking.

To analyse distribution patterns in the study cohort and to determine 5-year disease-specific survival, $\chi^{2}$ tests, and KaplanMeier analysis with log-rank tests were performed for the age groups defined above. The distributions of demographic, clinical, histologic, and treatment characteristics were compared using the $\chi^{2}$ test. Survival analysis was performed using the Kaplan-Meier estimates of survival probability across all three age groups, and the Cox-proportional hazards model was used to identify independent predictors of survival (Figure 1). The outcome of interest was death from ovarian cancer (disease-specific survival) and time to death was censored in women who died from causes other than ovarian cancer. Statistical analysis was performed using the Intercooled STATA 8.0 program (College Station, TX, USA). A two-sided $P$-value $<0.05$ was considered statistically significant.

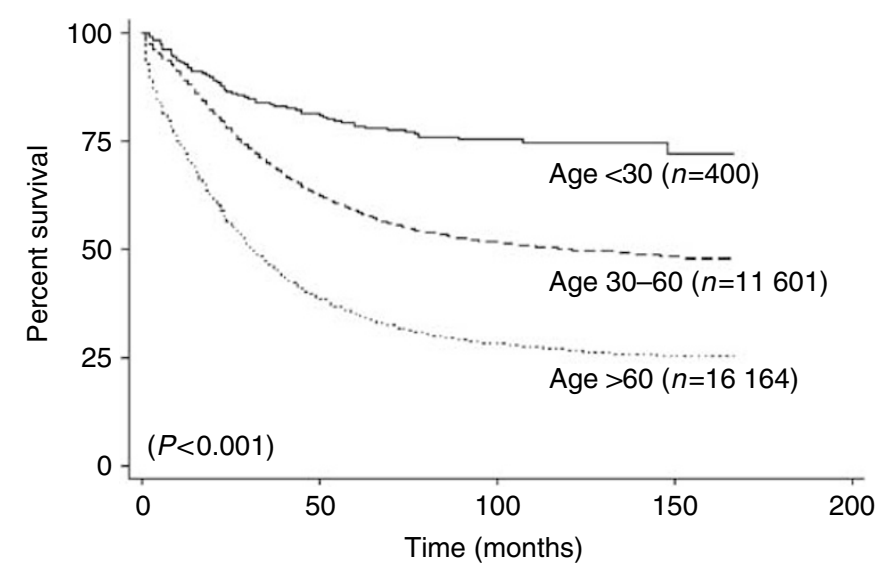

Figure I Kaplan-Meier disease-specific survival of patients based on age at diagnosis.

\section{RESULTS}

28165 patients were diagnosed with primary epithelial ovarian cancer from 1988 to 2001. We divided our young patient population into two groups: the very young group ( $<30$ years) consisting of 400 women and the young group (30-60 years) with 11601 patients. To provide a means for comparison, 16164 older patients ( $>60$ years) were used as controls. The median age of the young and very young patients was 26 (range: $12-29$ ) and 50 years (range: $30-60$ ), respectively. In contrast, the median age for the control group was 72 years (range: $61-101$ ).

Although the majority of patients in the three age groups were White, they comprised a significantly higher proportion of older patients as compared to younger patients $(78.3 \%$ for very young, $83.6 \%$ for young, and $89.2 \%$ for the older group; $P<0.001$ ). In contrast, Black subjects comprised $7.8 \%$ of the very young, $6.1 \%$ young, and only $5.6 \%$ of the older age group $(P<0.001)$. Similarly, other minority groups such as Asians and Hispanics are more heavily represented in the younger age groups (Table 1).

The very young and young patients were more likely to undergo a primary surgical procedure at 96.5 and $93.1 \%$ compared to $73.0 \%$ in the older age group (Table 2). More specifically, the very young patients are more likely to receive a uterine-preserving procedure compared to the older age groups (71.2 vs 14.1 vs $15.6 \%$, respectively; $P<0.001)$. Of those who underwent standard surgery, $4628(24.8 \%), 1715$ (9.2\%), $7334(39.2 \%)$, and $5018(26.8 \%)$ had stage I, II, III, and IV disease. Moreover, of the women who had uterine-sparing procedures, $1393(32.5 \%)$ had stage I disease, 306 (7.1\%) stage II, $1343(31.3 \%)$ stage III, and $1243(29.0 \%)$ had stage IV disease.

In the overall study group, $22.3 \%$ had stage I, $8.2 \%$ stage II, $35.9 \%$ stage III, and $33.7 \%$ had stage IV disease. Younger patients were diagnosed with significantly more early-stage disease than older patients. In fact, 65.3 and $40.2 \%$ of the very young and young age groups presented with stage I-II disease compared to only $22.5 \%$ in the $>60$ age group $(P<0.001)$. Younger patients were also more likely to be diagnosed with grade 1 disease with 33.8 and $12.0 \%$ of those in the very young and young group having welldifferentiated tumours compared to only $5.4 \%$ in the older patients $(P<0.001)$. In the entire study group, $1411(4.7 \%)$ were clear cell cancers of the ovary. There were no significant differences in the various histologic cell types amongst the three age groups.

The overall 5-year disease-specific survivals of women $<30,30-$ 60 , and $>60$ age groups were $78.8,58.8$, and $35.3 \%$, respectively $(P<0.001$; Table 3$)$. Of those with early-stage disease, the very young and young patients had a significant survival advantage at 89.7 and $88.8 \%$ compared to $74.5 \%$ in the older age group $(P<0.001)$. Similarly, older women with advanced-stage disease had poorer survival at only $22.1 \%$ compared to 55.7 and $36.9 \%$ in the very young and younger women $(P<0.001)$. Younger age continues to portend for a better prognosis across ethnic, histologic cell types, and year of diagnosis. Furthermore, younger age $(P<0.001)$, more recent year of diagnosis $(P<0.001)$, nonclear cell epithelial histologic cell types $(P<0.001)$, earlier stage of disease (Stage I $v s$ Stage II $v s$ Stage III $v s$ Stage IV, $P<0.001$ ), lower grade $(P<0.001)$, and surgical treatment (no surgery $v s$ any surgery, $P<0.001)$ remained as independent prognostic factors for improved survival (Table 4 ). When data for patients $<30$ years, $30-60$ and $>60$ years were analysed, similar results confirming the importance of age as an independent prognostic factor groups were found (hazard ratio $=1.20,95 \% \mathrm{CI}=1.13-1.28 ; P<0.001$ ).

Interestingly, reproductive age women, age 16-40, with stage I-II epithelial ovarian cancer who underwent uterine-sparing surgical procedures $(n=435)$ had similar rates of survival compared to their counterparts $(n=620)$ who underwent standard surgery ( 93.3 vs $91.5 \% ; P=0.26)$. Furthermore, there were no significant survival differences associated with these two surgical approaches in those with stage I-II non-clear cell epithelial 
Table I Demographic data

\begin{tabular}{|c|c|c|c|c|c|}
\hline & $\begin{array}{c}\text { Total }(n=28 \text { l65) } \\
n(\%)\end{array}$ & $\begin{array}{c}\text { Age }<30(n=400) \\
n(\%)\end{array}$ & $\begin{array}{c}\text { Age } 30-60(n=11601) \\
n(\%)\end{array}$ & $\begin{array}{c}\text { Age }>60(n=16 \quad 164) \\
n(\%)\end{array}$ & $\begin{array}{c}\chi^{2} \\
P \text {-values }\end{array}$ \\
\hline \multicolumn{6}{|l|}{ Age at diagnosis } \\
\hline \multicolumn{6}{|l|}{ Race } \\
\hline $\begin{array}{l}\text { White } \\
\text { Non-Hispanic } \\
\text { Hispanic } \\
\text { Black } \\
\text { Asian } \\
\text { Other }\end{array}$ & $\begin{array}{c}24424(86.7 \%) \\
22487(92.1 \%) \\
1937(7.9 \%) \\
1638(5.8 \%) \\
1496(5.3 \%) \\
607(2.2 \%)\end{array}$ & $\begin{array}{l}313(78.3 \%) \\
258(82.4 \%) \\
55(17.6 \%) \\
31(7.8 \%) \\
32(8.0 \%) \\
24(6.0 \%)\end{array}$ & $\begin{array}{c}9698(83.6 \%) \\
8715(89.9 \%) \\
983(10.1 \%) \\
702(6.1 \%) \\
841(7.2 \%) \\
360(3.1 \%)\end{array}$ & $\begin{array}{c}14413(89.2 \%) \\
13514(93.8 \%) \\
899(6.2 \%) \\
905(5.6 \%) \\
623(3.9 \%) \\
223(1.4 \%)\end{array}$ & $<0.001^{a}$ \\
\hline \multicolumn{6}{|l|}{ Year of diagnosis } \\
\hline $\begin{array}{l}\mid 988-1992 \\
\mid 993-1997 \\
|998-200|\end{array}$ & $\begin{array}{r}8277(29.4 \%) \\
10812(38.4 \%) \\
9076(32.2 \%)\end{array}$ & $\begin{array}{l}157(39.3 \%) \\
131(32.8 \%) \\
112(28.0 \%)\end{array}$ & $\begin{array}{l}3218(27.7 \%) \\
4416(38.1 \%) \\
3967(34.2 \%)\end{array}$ & $\begin{array}{l}4902(30.3 \%) \\
6265(38.8 \%) \\
4997(30.9 \%)\end{array}$ & $<0.001$ \\
\hline
\end{tabular}

${ }^{a}$ Comparing Non-Hispanic, Hispanic, Black, Asian, and Other race; when comparing White, Black, Asian, and other race, $P<0.00$ I. ${ }^{b}$ Includes Chinese, Japanese, Filipina, Korean, and Vietnamese.

Table 2 Clinico-pathologic and treatment data

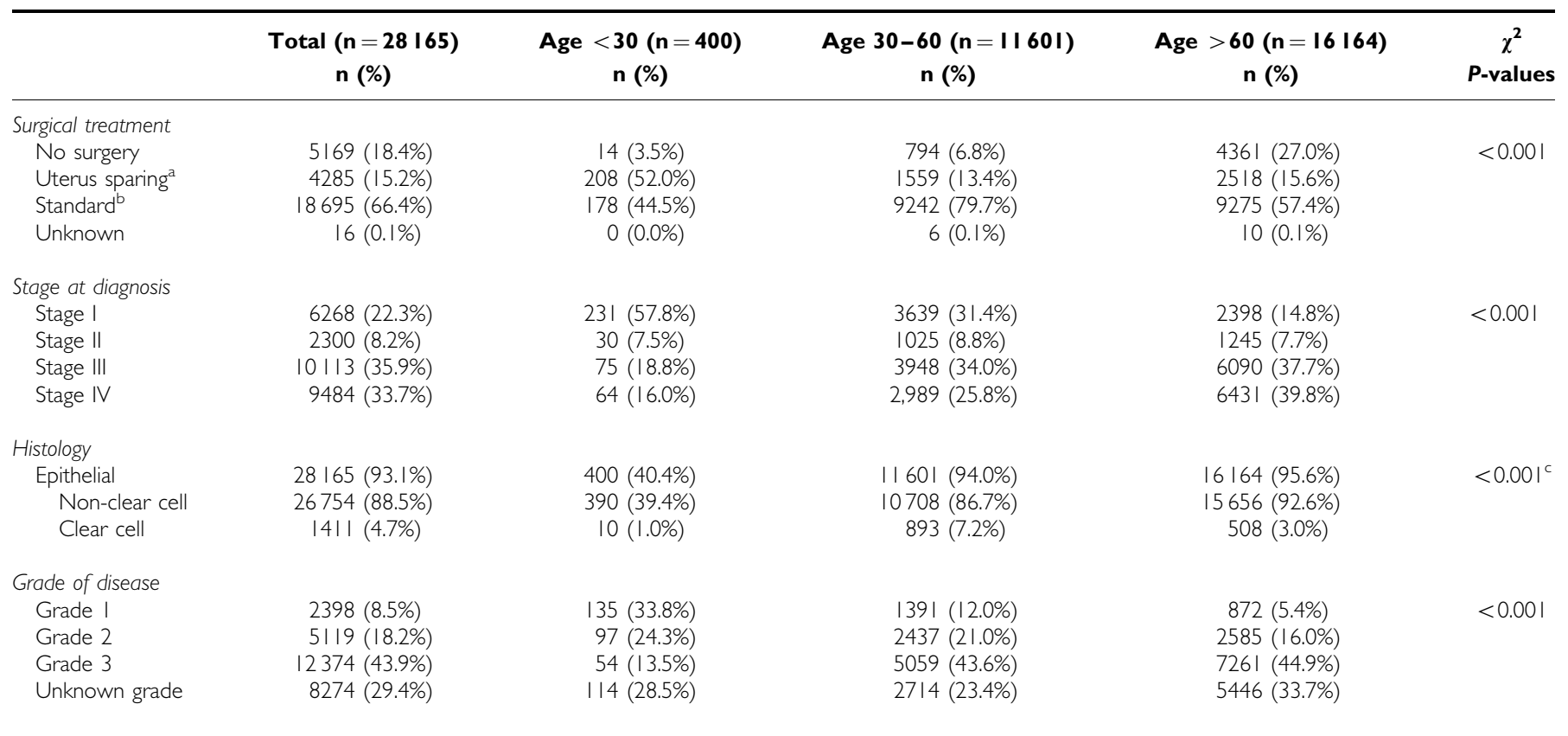

a Uterus-sparing surgeries, including minimal surgery or surgeries that did not include a hysterectomy. ${ }^{b}$ Standard surgeries, including surgeries including a hysterectomy and/or debulking. ${ }^{c}$ Compares non-clear cell epithelial with clear cell.

tumours $(94.0 \%(n=449)$ vs $92.4 \%(n=719) ; P=0.41$, Figure $2 \mathrm{~A})$ or stage I- II clear cell cancers $(72.9 \%(n=20)$ vs $84.8 \%(n=77)$; $P=0.73$, Figure 2B). Even in patients with stage IIIC disease, we were unable to demonstrate a statistically significant survival difference $(49.6 \% \quad(n=27) \quad$ vs $68.9 \% \quad(n=258)$, respectively; $P=0.22)$.

\section{DISCUSSION}

Ovarian cancer is primarily a disease of postmenopausal women. Previous studies have shown that only $3-17 \%$ of patients with ovarian cancer were age $<40$ years (Plaxe et al, 1993; Rodriguez et al, 1994). The reported prognostic significance of age in female cancers has been inconsistent. Younger age has been shown to be a poor prognosticator in breast cancer. Recently, Maggard and others have demonstrated that younger $(<35)$ women with breast cancer have a poorer prognosis owing to higher stage and grade of disease at presentation (Yildirim et al, 2000; Biffl et al, 2001; Xiong et al, 2001; Dubsky et al, 2002; Kothari et al, 2002; Love et al, 2002; Maggard et al, 2003). However, studies on the prognostic implications of age and ovarian cancer are inconclusive. Although most reports have shown that younger women with ovarian cancer have an improved outcome compared to older women and have lower stage and more well-differentiated tumours (Smedley and Sikora, 1985; Plaxe et al, 1993; Thigpen et al, 1993; Rodriguez et al, 1994; Chan et al, 2003), others have found that age is not an independent prognostic factor after adjusting for tumour stage and grade (Massi et al, 1996; Duska et al, 1999). Moreover, the majority of these previous studies on ovarian cancer are based on single 
Table 3 Disease-specific 5-year survival by demography and clinico-pathology

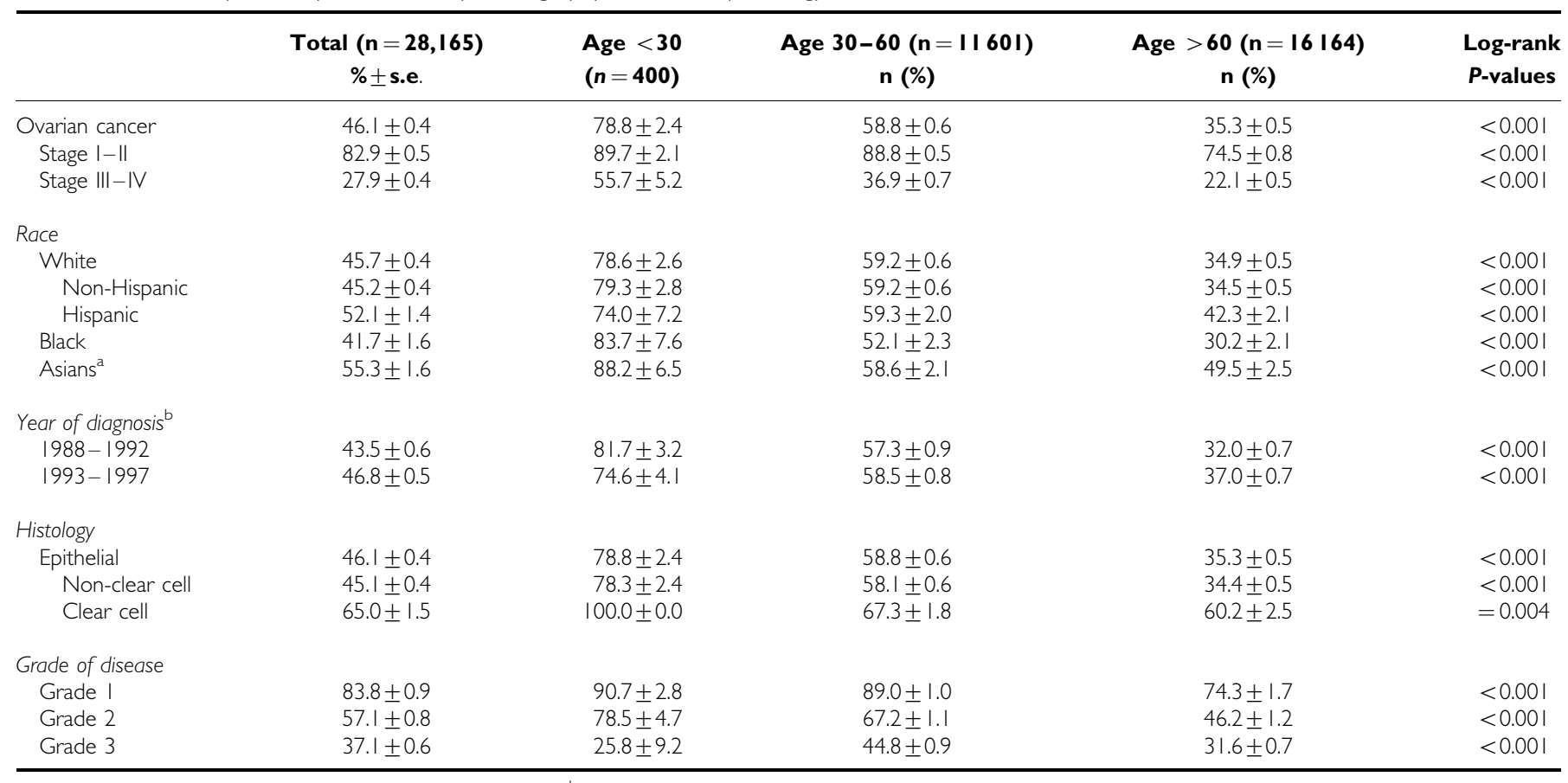

ancludes Chinese, Japanese, Filipina, Korean, and Vietnamese. ${ }^{b}$ 1998-200I time period not included as follow-up is not mature enough to yield 5-year survivals.

Table 4

Multivariate analysis

\begin{tabular}{lccc}
\hline & Hazard ratio & Confidence interval & $P$-value \\
\hline Stage of disease $^{a}$ & 1.93 & $(1.89-1.97)$ & $P<0.001$ \\
Histologic cell type $^{b}$ & 1.27 & $(1.15-1.40)$ & $P<0.001$ \\
Age at diagnosis $^{c}$ & 1.02 & $(1.02-1.02)$ & $P<0.001$ \\
Grade of disease $^{d}$ & 1.02 & $(1.01-1.03)$ & $P<0.001$ \\
Year of diagnosis $^{c}$ & 0.99 & $(0.98-0.99)$ & $P<0.001$ \\
Surgical treatment $^{\mathrm{e}}$ & 0.69 & $(0.68-0.71)$ & $P<0.001$ \\
Race/Ethnicity $^{f}$ & 0.99 & $(0.96-1.02)$ & $P=0.71$ \\
\hline
\end{tabular}

${ }^{a}$ Stage I vs Stage II vs Stage III vs Stage IV. ${ }^{\text {b} N o n-c l e a r ~ c e l l ~ e p i t h e l i a l ~ c a n c e r ~ v s ~ c l e a r ~ c e l l ~}$ cancer. 'As a continuous variable. 'Grade I vs Grade 2 vs Grade 3 vs unknown Grade. ${ }^{e}$ No surgery vs any surgery. 'White vs Black vs Asians vs Others.

institution experiences, which contain inherent biases such as patient selection (Plaxe et al, 1993; Duska et al, 1999; Chan et al, 2003). In addition, owing to the low prevalence of young patients diagnosed with invasive ovarian cancer, these studies have also been limited by a small number of patients, inclusion of low malignant potential tumours, germ cell or sex cord stromal tumours, and unstaged cancers. European analyses on ovarian cancer incidence rates include studies carried out by Smedley and Sikora (1985), La Vecchia et al (1992), dos Santos Silva and Swerdlow (1995), Koper et al (1996), Nelson et al (1999). Given the limitations from prior reports, we proposed to perform a large population-based study to evaluate the clinico-pathologic characteristics between younger and older patients with epithelial ovarian cancer. Furthermore, we sought to determine if younger age is an independent prognostic factor for improved survival and analyze the safety of uterine-sparing surgery in reproductive-age women.

The finding that young women tend to have more indolent grade 1 tumours may contribute to their earlier stage at presentation and overall good prognosis. Although lower grade and earlier stage may partially explain the better survival of younger patients with ovarian cancer, younger age was an independent prognostic factor for improved survival in our multivariable analysis. Beyond conventional pathologic prognostic factors, other important molecular markers include p53 expression, Her2neu, and DNA ploidy can also help elucidate the survival differences between younger and older women (Trope et al, 2000; Nagai et al, 2001; Skirnisdottir et al, 2001; Chan et al, 2004; Nishimura et al, 2005; Serrano-Olvera et al, 2006). Studies have shown that younger patients had tumours with higher microvascular density which may be associated with an improved response to paclitaxel/ platinum-based chemotherapy (Hartmann et al, 1994; Kosary, 1994; Chan et al, 2004). Our results reflect that of other studies showing that younger age is an independent prognosticator for improved survival (Yancik et al, 1986; Ries, 1993; Kosary, 1994; Rodriguez et al, 1994; Barnholtz-Sloan et al, 2003; O'Malley et al, 2003). Nevertheless, this current reports is one of the largest population-based studies that has evaluated the demographic and clinico-pathologic prognostic factors associated with the survival of younger women with ovarian cancer using detailed surgical staging and pathologic information.

Some studies have reported that younger women are able to tolerate more intensive chemotherapeutic regimens which may explain the better outcome in these patients (Thigpen et al, 1993; Kosary, 1994). On the other hand, case-controlled studies from single academic institutions adjusting for the experience of surgeon, extent of surgery, and adjuvant chemotherapy, younger age remained a significant independent factor for improved survival (Duska et al, 1999; Chan et al, 2003). In addition, Chan et al (2003) showed that younger age was an important prognostic factor for improved survival independent of age-associated determinants such as performance status. Similar findings were also reported by Thigpen et al (1993) who analysed a large series of patients with stage III and IV invasive epithelial ovarian cancer from six Gynecologic Oncology Group trials where strict guidelines were maintained to ensure that all patients underwent similar surgical procedures and standard adjuvant chemotherapy.

Given the large number of patients in this current study, we were able to divide our patient population into three subsets; those $<30,30-60$, and $>60$ years. It was not surprising to find that the women $<30$ were more likely to have grade 1 and early-stage 

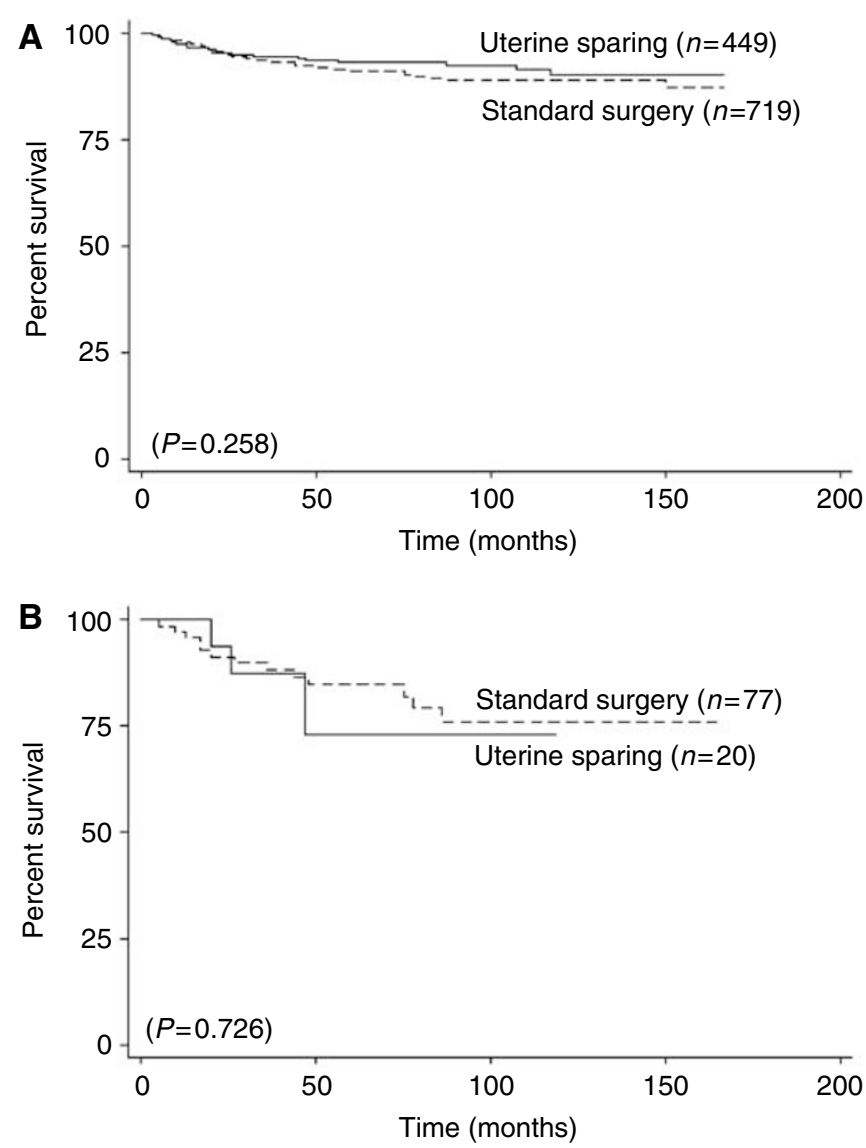

Figure 2 Kaplan-Meier disease-specific survival of reproductive age patients (age 16-40 years) with stage I-II (A) epithelial and (B) clear cell ovarian cancer.

cancers. In fact, over $40 \%$ of ovarian cancers in the age 30-60 cohort had early-stage disease compared to less than $25 \%$ in the older cohort.

The potential role of fertility-sparing surgery in reproductive age women diagnosed with ovarian cancer has received considerable attention. In a national survey of ovarian cancer evaluating women age $<25$ years with ovarian malignancies, Rodriguez et al (1994) demonstrated that the rate of fertility-sparing surgery has increased from 46 to $70 \%$ over the 5 -year study period. In this current report, we showed that uterine-sparing surgery was performed on $38.1 \%$ of reproductive age women with early-stage epithelial ovarian cancer. However, because the SEER database does not provide information regarding the extent of surgical debulking and desire to retain fertility, it is difficult to definitively validate or refute the possibilities that uterine-sparing surgery may represent suboptimally debulked patients in older women or be indicative of a desire to retain fertility in younger patients with advanced-stage disease. Nonetheless, our analyses did not find any survival difference between these women who underwent a uterine-sparing procedure compared to those that had standard surgeries in early-stage cancers $(P=0.26)$. In a sub-analysis comparing women with stage I-II non-clear cell $v s$ clear cell cancers, we found that there was still no survival difference based on the type of surgical procedure performed (non-clear cell epithelial cancer, $P=0.41$; clear cell, $P=0.73$ ). We recognise that the survival of young patients appears to have decreased over the two time periods (1988-1992; 1993-1997); however, the difference was not statistically significant $(P=0.47)$ and is likely owing to the small number of patients within each group $(<200)$. We also performed an additional analysis on the use of uterine-sparing surgeries between these two groups and identified a trend towards an increase in the use of conservative surgery over time, though, again, statistically insignificant $(49.7-55.0 \% ; P=0.66)$. Thus, it is unlikely that uterine-sparing surgeries could have contributed to the suggested findings. Although this retrospective data suggests that uterine-sparing surgeries may be considered in reproductiveage women, patients should be counselled appropriately with an understanding of the risks.

Our study was limited by the lack of information on surgeon specialty, extent of residual disease, adjuvant chemotherapy, and subsequent cytoreductive surgeries. Given that our data was derived from a nationwide cancer registry, it has shortcomings with respect to detailed clinical information such as family history, presenting symptoms, performance status, and time from symptom to presentation which may help to enhance our understanding of the underlying causes for the survival differences between the age groups. As with other large population-based series, our report was also limited by a lack of central pathology review. To determine if there are significant discrepancies between registry and referral pathologists, Piver et al (2000) reviewed slides from a large cancer registry and found a $95.3 \%$ complete agreement between pathologists on the disease site of origin. Moreover, there was a $61.7 \%$ complete histopathologic agreement with only $1 \%$ of cases that were considered as having major differences. Similarly, Tyler et al (1991) performed slide reviews on 477 women diagnosed with ovarian, breast, or endometrial cancer and compared the diagnoses of pathologists contributing to tumour registries affiliated with the SEER program to an expert panel of three gynaecologic pathologists. They found an overall agreement of $97 \%$ for overall cancers, and the agreement for major cellular subtypes of ovarian cancer was $73 \%$ for endometrioid and $100 \%$ for clear cell cancers.

The strength of this study lies in the large number of young patients with surgically staged invasive ovarian cancer, offering the ability to perform detailed, stratified analyses without sacrificing statistical strength. Furthermore, we excluded all women diagnosed with low malignant potential tumours, sarcomas, germ cell, and sex cord stromal tumours. Given that younger women are more likely to be diagnosed with borderline tumours, the inclusion of these patients may partially explain the better survival of younger women in prior studies. Additionally, this current study is one of the largest series to date of unselected patients spanning across 12 US regions, allowing for the attenuation of selection and surveillance biases often associated with clinical trials and studies from single academic institutions. Because SEER cancer registries are consistent with those for the entire country, the results from this population-based study can be generalised to the national population (Hankey et al, 1999). Most importantly, SEER uses several quality control measures to ensure accuracy; thus, they are able to maintain the highest level of certification of data quality and completeness as reported by the Northern American Association of Central Cancer Registries. SEER adheres to strict quality assessment measures by ensuring the accuracy of sample cases by reabstracting data from the medical records annually. Based on a recent studies by Virnig et al (2002), these authors found a $98 \%$ completeness in each sample case with a $>90 \%$ rate in the accuracy of reporting adjuvant therapy (Virnig et al, 2002; Maggard et al, 2003). In addition, the database also appears to be accurate for major surgical procedures (Cooper et al, 2002).

In summary, this is one of the largest studies to date defining the status of young patients diagnosed with epithelial ovarian cancer. We found that younger patients have a better survival compared to their older cohort. Clearly, early stage and lower grade are in part responsible for the improved survival of these young women. However, after controlling for these clinico-pathologic prognostic factors, the younger group still had a better prognosis, suggests that there maybe other underlying factors such as tumour biology that can explain these findings. This analysis also suggests that reproductive-age women who undergo surgical staging should be 
offered conservative treatment with uterine-sparing surgeries. Moreover, given the overall encouraging outcome of younger women diagnosed with ovarian cancer, these patients need to be treated aggressively. Further research to investigate the potential biologic and molecular difference between epithelial ovarian tumours in various age groups is warranted.

\section{REFERENCES}

Averette HE, Janicek MF, Menck HR (1995) The national cancer data base report on ovarian cancer. american college of surgeons commission on cancer and the american cancer society. Cancer 76: 1096-1103

Barnholtz-Sloan JS, Schwartz AG, Qureshi F, Jacques S, Malone J, Munkarah AR (2003) Ovarian cancer: changes in patterns at diagnosis and relative survival over the last three decades. Am J Obstet Gynecol 189: $1120-1127$

Biffl WL, Myers A, Franciose RJ, Gonzalez RJ, Darnell D (2001) Is breast cancer in young Latinas a different disease? Am J Surg 182: 596-600

Brun JL, Feyler A, Chene G, Saurel J, Brun G, Hocke C (2000) Long-term results and prognostic factors in patients with epithelial ovarian cancer. Gynecol Oncol 78: 21-27

Chan JK, Loizzi V, Lin YG, Osann K, Brewster WR, DiSaia PJ (2003) Stages III and IV invasive epithelial ovarian carcinoma in younger $v s$ older women: what prognostic factors are important? Obstet Gynecol 102: 156-161

Chan JK, Loizzi V, Magistris A, Lin F, Rutgers J, Osann K, Disaia PJ, Berman ML (2004) Differences in prognostic molecular markers between women over and under 45 years of age with advanced ovarian cancer. Clin Cancer Res 10: 8538-8543

Cooper GS, Virnig B, Klabunde CN, Schussler N, Freeman J, Warren JL (2002) Use of SEER-Medicare data for measuring cancer surgery. Med Care 40: IV -43-8

dos Santos Silva I, Swerdlow AJ (1995) Recent trends in incidence of and mortality from breast, ovarian and endometrial cancers in England and Wales and their relation to changing fertility and oral contraceptive use. Br J Cancer 72: 485-492

Dubsky PC, Gnant MF, Taucher S, Roka S, Kandioler D, Pichler-Gebhard B, Agstner I, Seifert M, Sevelda P, Jakesz R (2002) Young age as an independent adverse prognostic factor in premenopausal patients with breast cancer. Clin Breast Cancer 3: 65-72

Duska LR, Chang YC, Flynn CE, Chen AH, Goodman A, Fuller AF, Nikrui N (1999) Epithelial ovarian carcinoma in the reproductive age group. Cancer 85: 2623-2629

Gloecker-Ries L (1993) Ovarian cancer. Survival and treatment differences by age. Cancer 7(Suppl 2): $524-529$

Hankey BF, Ries LA, Edwards BK (1999) The surveillance, epidemiology, and end results program: a national resource. Cancer Epidemiol Biomarkers Prev 8: $1117-1121$

Hartmann LC, Podratz KC, Keeney GL, Kamel NA, Edmonson JH, Grill JP, Su JQ, Katzmann JA, Roche PC (1994) Prognostic significance of p53 immunostaining in epithelial ovarian cancer. J Clin Oncol 12: 64-69

Jemal A, Tiwari RC, Murray T, Ghafoor A, Samuels A, Ward E, Feuer EJ, Thun MJ (2004) Cancer statistics, 2004. CA Cancer J Clin 54: 8-29

Koper NP, Kiemeney LA, Massuger LF, Thomas CM, Schijf CP, Verbeek AL (1996) Ovarian cancer incidence (1989-1991) and mortality (1954-1993) in The Netherlands. Obstet Gynecol 88: 387-393

Kosary CL (1994) FIGO stage, histology, histologic grade, age and race as prognostic factors in determining survival for cancers of the female gynecological system: an analysis of 1973-87 SEER cases of cancers of the endometrium, cervix, ovary, vulva, and vagina. Semin Surg Oncol 10: $31-46$

Kothari AS, Beechey-Newman N, D’Arrigo C, Hanby AM, Ryder K, Hamed $\mathrm{H}$, Fentiman IS (2002) Breast carcinoma in women age 25 years or less. Cancer 94: 606-614

La Vecchia C, Levi F, Lucchini F, Negri E, Franceschi S (1992) Descriptive epidemiology of ovarian cancer in Europe. Gynecol Oncol 46: 208-215

Lee CK, Pires de Miranda M, Ledermann JA, Ruiz de Elvira MC, Nelstrop AE, Lambert HE, Rustin GJ, Trask CW (1999) Outcome of epithelial ovarian cancer in women under 40 years of age treated with platinumbased chemotherapy. Eur J Cancer 35: 727-732

Love RR, Duc NB, Dinh NV, Quy TT, Xin Y, Havighurst TC (2002) Young age as an adverse prognostic factor in premenopausal women with operable breast cancer. Clin Breast Cancer 2: 294-298

Maggard MA, O'Connell JB, Lane KE, Liu JH, Etzioni DA, Ko CY (2003) Do young breast cancer patients have worse outcomes? J Surg Res 113: $109-113$
Massi D, Susini T, Savino L, Boddi V, Amunni G, Colafranceschi M (1996) Epithelial ovarian tumors in the reproductive age group: age is not an independent prognostic factor. Cancer 77: 1131-1136

Nagai N, Oshita T, Fujii T, Katsube Y, Matsubayashi S, Ohama K (2001) Are DNA ploidy and epidermal growth factor receptor prognostic factors for untreated ovarian cancer? A prospective study. Am J Clin Oncol 24: $215-221$

Nelson L, Ekbom A, Gerdin E (1999) Ovarian cancer in young women in Sweden, 1989-1991. Gynecol Oncol 74: 472-476

Nguyen HN, Averette HE, Hoskins W, Sevin BU, Penalver M, Steren A (1993) National survey of ovarian carcinoma. VI. Critical assessment of current International Federation of Gynecology and Obstetrics staging system. Cancer 72: 3007-3011

Nishimura N, Hachisuga T, Yokoyama M, Iwasaka T, Kawarabayashi T (2005) Clinicopathologic analysis of the prognostic factors in women with coexistence of endometrioid adenocarcinoma in the endometrium and ovary. J Obstet Gynaecol Res 31: 120-126

North American Association of Central Cancer Registries Available at http://wwwnaaccrorg/ Surveillance Epidemiology, End Results (SEER) Program, www.seer.cancer.gov SEER ${ }^{*}$ Stat Database: Incidence - SEER 9 Regs Public-Use, November 2004 Sub (1973-2002), National Cancer Institute, DCCPS, Surveillance Research Program, Cancer Statistics Branch, released April 2005.

O'Malley CD, Cress RD, Campleman SL, Leiserowitz GS (2003) Survival of Californian women with epithelial ovarian cancer, 1994-1996: a population-based study. Gynecol Oncol 91: 608-615

Omura GA, Brady MF, Homesley HD, Yordan E, Major FJ, Buchsbaum HJ, Park RC (1991) Long-term follow-up and prognostic factor analysis in advanced ovarian carcinoma: the Gynecologic Oncology Group experience. J Clin Oncol 9: 1138-1150

Parker SL, Tong T, Bolden S, Wingo PA (1996) Cancer statistics. CA Cancer J Clin 46: 5-27

Piver MS, Tsukada Y, Werness BA, DiCioccio RA, Whittemore AS, Ponder BA (2000) Comparative study of ovarian cancer histopathology by registry pathologists and referral pathologists: a study by the Gilda Radner Familial Ovarian Cancer Registry. Gynecol Oncol 78: 166-170

Plaxe SC, Braly PS, Freddo JL, McClay E, Kirmani S, Howell SB (1993) Profiles of women age $30-39$ and age less than 30 with epithelial ovarian cancer. Obstet Gynecol 81: 651-654

Ries LA, Kosary CL, Hankey BF, Miller BA, Clegg L, Mariotto A, Feuer EJ, Edwards BK (2004) SEER Cancer Statistics Review, 1975-2001. National Cancer Institute: Bethesda, MD

Ries LA (1993) Ovarian cancer. Survival and treatment differences by age. Cancer 71: 524-529

Rodriguez M, Nguyen HN, Averette HE, Steren AJ, Penalver MA, Harrison T, Sevin BU (1994) National survey of ovarian carcinoma XII. Epithelial ovarian malignancies in women less than or equal to 25 years of age. Cancer 73: $1245-1250$

Schildkraut JM, Halabi S, Bastos E, Marchbanks PA, McDonald JA, Berchuck A (2000) Prognostic factors in early-onset epithelial ovarian cancer: a population-based study. Obstet Gynecol 95: 119-127

Serrano-Olvera A, Duenas-Gonzalez A, Gallardo-Rincon D, Candelaria M, De la Garza-Salazar J (2006) Prognostic, predictive and therapeutic implications of HER2 in invasive epithelial ovarian cancer. Cancer Treat Rev 32: $180-190$

Skirnisdottir I, Sorbe B, Karlsson M, Seidal T (2001) Prognostic importance of DNA ploidy and p53 in early stages of epithelial ovarian carcinoma. Int J Oncol 19: 1295-1302

Smedley H, Sikora K (1985) Age as a prognostic factor in epithelial ovarian carcinoma. Br J Obstet Gynaecol 92: 839-842

Swenerton KD, Hislop TG, Spinelli J, LeRiche JC, Yang N, Boyes DA (1985) Ovarian carcinoma: a multivariate analysis of prognostic factors. Obstet Gynecol 65: $264-270$

Thigpen T, Brady MF, Omura GA, Creasman WT, McGuire WP, Hoskins WJ, Williams S (1993) Age as a prognostic factor in ovarian carcinoma. The Gynecologic Oncology Group experience. Cancer 71: 606-614 
Trimble EL, Kosary C, Park RC (1998) Lymph node sampling and survival in endometrial cancer. Gynecol Oncol 71: $340-343$

Trope C, Kaern J, Hogberg T, Abeler V, Hagen B, Kristensen G, Onsrud M, Pettersen E, Rosenberg P, Sandvei R, Sundfor K, Vergote I (2000) Randomized study on adjuvant chemotherapy in stage I high-risk ovarian cancer with evaluation of DNA-ploidy as prognostic instrument. Ann Oncol 11: $281-288$

Tyler Jr CW, Lee NC, Robboy SJ, Kurman RJ, Paris AL, Wingo PA, Williamson GD (1991) The diagnosis of ovarian cancer by pathologists: how often do diagnoses by contributing pathologists agree with a panel of gynecologic pathologists? Am J Obstet Gynecol 164: $65-70$
Virnig BA, Warren JL, Cooper GS, Klabunde CN, Schussler N, Freeman J (2002) Studying radiation therapy using SEER-Medicare-linked data. Med Care 40: IV -49-54

Xiong Q, Valero V, Kau V, Kau SW, Taylor S, Smith TL, Buzdar AU, Hortobagyi GN, Theriault RL (2001) Female patients with breast carcinoma age 30 years and younger have a poor prognosis: the M.D. Anderson Cancer Center experience. Cancer 92: 2523-2528

Yancik R, Ries LG, Yates JW (1986) Ovarian cancer in the elderly: an analysis of Surveillance, Epidemiology, and End Results Program data. Am J Obstet Gynecol 154: 639-647

Yildirim E, Dalgic T, Berberoglu U (2000) Prognostic significance of young age in breast cancer. J Surg Oncol 74: 267-272 